\title{
Pediatric obesity: prevention is better than care
}

\author{
Roberta Romanelli ${ }^{1}$, Nicola Cecchi ${ }^{1}$, Maria Grazia Carbone1, Michele Dinardo', Giuseppina Gaudino², \\ Emanuele Miraglia del Giudice ${ }^{2}$ and Giuseppina Rosaria Umano ${ }^{2^{*}}$ (i)
}

\begin{abstract}
Pediatric obesity is one of the most relevant health issues of the last century. Obesity-related short and long-term consequences are responsible of a large amount of economic cost. In addition, the different therapeutic strategies, such as lifestyle correction, drug, and bariatric surgery have displayed low effectiveness. Considering this evidence, prevention appears to be more promising than treatment in contrasting obesity epidemic. In this review, we summarize obesity pathogenesis with the aim of highlight the main obesity risk factors that can be addressed as target of preventive interventions. Moreover, we report the evidence about effectiveness of different interventions targeting family, school, and community. A multiple-component intervention, addressing different targets and settings, might be desirable, however more studies are needed to confirm long-term efficacy and to direct policy interventions.
\end{abstract}

Keywords: Childhood obesity, Obesity prevention intervention, Family-based intervention, School-based intervention, Public health intervention

\section{Introduction}

World Health Organization describes pediatric obesity epidemic as "one of the most serious public health challenges of the $21^{\text {st }}$ century" [1]. Recent estimates from WHO revealed that obesity prevalence has increased three times from 1975 to 2016 [2] and that about 41 million children aged under 5 years and 340 million children and adolescents aged 5-19 years are affected by overweight or obesity [3]. In Italy, about 21.3 and 9.3\% of school-aged children are overweight and obese, respectively [4].

Obesity-related health costs derive also from its short and long-term comorbidities. Firstly, obese children are at higher risk of glucose intolerance [5], non-alcoholic fatty liver disease [6], dyslipidemia [7], and hypertension

\footnotetext{
* Correspondence: giusi.umano@gmail.com

${ }^{2}$ Department of the Woman, of the Child, of General and Specialized

Surgery, University of Campania "Luigi Vanvitelli", Via L. de Crecchio, 2, 80138 Naples, Italy

Full list of author information is available at the end of the article
}

[8]. In addition, childhood obesity tends to persist during adulthood. It has been estimated that about $80 \%$ of severe obese children at the age of 2 years will be obese during adulthood [9]. Moreover, several evidence link childhood obesity to the burden of Non-Communicable Diseases in adult population [10-14]. Obesity is responsible for increased risk of type 2 diabetes [10], cardiovascular disease [11, 12], finally leading to increased morbidity and mortality $[13,14]$.

Despite scientific and clinical efforts, current therapies, including education, diet, exercise, drug, and bariatric surgery, to reduce obesity are failing to provide effective long-term results [15].

In view of this evidence, there is a strong need to identify the major obesity risk factors and to promote effective interventions to prevent obesity epidemic and its long-term consequences. In this review, we summarize the current knowledge about childhood obesity risk factors and prevention studies. 


\section{Obesity pathogenesis}

Obesity is a complex disease and the chronic mismatch between caloric intake and expenditure has been recognized as the main mechanism of weight gain [16]. Western diet and commercial interests that induce the consumption of cheap, energy-dense, and low-innutrients foods and beverages and the concurrent sedentary lifestyle are the main drivers of the obesity epidemic [17]. In addition, social inequalities enhance the risk of obesity being a low socioeconomic status associated with higher prevalence of obesity $[18,19]$. However, not all the subjects exposed to an obesogenic environment develop obesity, therefore, over the past decades, genetic basis of obesity have been investigated.

\section{The role of genetics}

Genome wide association studies (GWASs) have reported the association between several single nucleotide polymorphisms (SNPs) and weight gain [20, 21]. Multiple gene variants might predispose subjects to gain weight in an obesogenic environment, this genetic form is referred as polygenic obesity [22, 23]. In addition to polygenic obesity, monogenic forms of obesity have been described. Single gene variations in the leptin-melanocortin hypothalamic pathway are responsible of severe early-onset obesity that are characterized by hyperphagia, rapid weight gain, and other possible endocrine dysfunctions [24-29]. However, monogenic obesities are responsible for a small percentage of obesity cases and cannot explain the obesity epidemic even if they increase the susceptibility to an obesogenic environment [30].

\section{The role of epigenetics}

During the last years, a great interest in the interaction between genes and environment has pointed out the role of epigenetics in obesity pathogenesis. Environmental factors can affect gene expression and activity influencing both transcription, translation, and post-translational processes without changing DNA sequence [22]. DNA transcription can be regulated by DNA methylation that inhibits the binding of transcriptional factors to gene promoter. In addition, histones acetylation can interfere with gene expression by changing chromatin structure. Finally, long non-coding RNA (lncRNA) and microRNA (miRNA) can affect RNA messenger levels and proteins production [31]. DNA methylation is the most investigated epigenetic change.

Epigenetic modifications are tissue-specific and might persist over time [32]. Intrauterine life and the first 2 years of life have been described as a crucial period for metabolic programming as the epigenome processes are more active and pliant [32]. Robust evidences have pointed out the association between maternal weight gain, health conditions, and tobacco smoke with offspring obesity [31,33]. One of the most important examples of the transgenerational transmission of obesity risk is the Dutch Hunger Winter of 1944. Children born around the Dutch famine that were exposed to maternal undernutrition and showed higher prevalence of obesity, glucose intolerance, and cardiovascular disease later in life [34]. Similarly, maternal obesity and the consequent elevation of glucose, fatty acids, and amino acids plasmatic levels can influence the development and regulation of appetite, neuroendocrine function, and energy balance promoting obesity [35].

Considering this evidence, the characterization of epigenetic changes and their role in childhood obesity might enable the identification of early markers of risk, therapeutic targets, and prevention strategies.

\section{The role of microbiota}

Human gut hosts a complex and large bacterial community called microbiota. The composition of gut microbiota depends on diet composition, as different substrates can promote or inhibit the growth of different phyla. For example, high intake of fiber and fermented food promotes a healthier and more diversified microbiota. Conversely, western diet is associated with an unhealthy composition of microbiota [36]. Bacteria colonization of human intestine begins with delivery and continues during early nutrition stages [37]. Therefore, it is essential to care nutrition during neonatal period and first years of life. In particular, breastfeeding has been associated with a healthier composition of microbiota compared to infant formula. In fact, maternal milk is able to transfer several phyla, such as Bifidobacterium, Streptococcus, and Lactobacillus, that can contribute to neonatal microbiota [37]. Animal and human studies have associated gut dysbiosis with obesity in adult and children with contrasting results [38, 39]. Composition of gut microbiota differs between obese and lean subjects [36]. In particular, obese subjects have a higher colonization by Firmicutes and reduced levels of Bacteroides and Prevotella and weight loss has been associated with a reconstitution of Bacteroides-Firmicutes ratio as in lean subjects [40]. The proposed pathogenesis underpinning gut dysbiosis-obesity relationship include several mechanisms, such as alteration of gut layer, modulation of immune system and inflammation, production of metabolites able to target other organs including adipose tissue and liver. In particular, certain bacterial groups produces short chain fatty acids (SCFAs) from indigestible fibers. SCFAs serve as energy source for colonocytes as well as are able to reach other tissues inducing gluconeogenesis, de novo lipogenesis, epigenetic modifications, and incretin secretion [36]. Nevertheless, the complexity of obesity pathogenesis does not allow to demonstrate a clear and independent role of gut microbiota in obesity even though evidence has been provided. 


\section{Obesity prevention}

With the exception of genetic predisposition to obesity, it is clear that there are different modifiable targets for preventing childhood obesity. Additionally, a multicomponent approach, including political, social, and educational programs, should be promoted. Moreover, a multi-level intervention starting from the child, to family, school, and community may be applied (Table 1). Tailoring the type of intervention to children age (Table 2).

\section{Family based interventions}

Given the central role of parents in controlling and influencing children's dietary habits, physical activity, and sleep, family-based prevention programs are promising tool in limiting obesity epidemic. As mentioned above, the early stages of life, from conception to 2 years of age, are associated with the risk of later obesity [41]. Parents weight control before conception and during pregnancy as well as tobacco smoke avoidance should be encouraged [41]. Therefore, educational sessions focusing on healthy diet, active lifestyle, and weight monitoring during pregnancy should be performed. Several evidences have pointed out the protective action of breastfeeding against obesity compared to formula feeding [42, 43]. In addition, excessive protein intake should be avoided during the first year of life [44-47]. Consequently, exclusive breastfeeding until 6 months and controlled protein intake after weaning should be encouraged [48, 49].

Several studies have investigated the effectiveness of prevention programs focused on the first 1000 days of life on weight gain with mixed findings. In particular, limited effect has been observed in anthropometric outcomes, but several behavioral improvements in terms of diet, lifestyle, and sleeping habits have been reported. The heterogeneity of the results can be attributed to the differences in intervention type and limited number of studies [50-52]. Therefore, more research is needed to recommend specific prevention programs.

Family dynamics are crucial in later ages too. During pre-school age, it is essential to promote healthy eating behaviors. Consequently, mealtime has a great importance as parents act as role models, educators, and health promoters of their children. Parents should offer a good variety of foods, in favor of fruits and vegetables, and should limit the consumption of sugar sweetened beverages [53, 54]. In addition, parents should take care of feeding practice during meals, offering a positive models in accepting new and healthy foods inducing imitation in the child [55]. A recent metanalysis reported that several parents' educational practices such as verbal praise, modeling, availability, and active were significantly associated with child healthy eating behavior. Conversely, pressuring children to eat, rewarding food consumption, and restrictive guidance had a negative association with healthy food consumption [53].

Paralleling with nutrition, family education practice should reduce mass media exposure as they expose the child to junk high-calories foods [56]. In addition, television viewing and use of tablets and videogames increase sedentary behavior and reduce the time spent in active games and sports. Therefore, screen time is associated with a significant increase of the risk of being overweight or obese [57].

Table 1 Obesity prevention interventions according to setting

\begin{tabular}{ll}
\hline Setting & Intervention \\
\hline Family & Parents weight control \\
& Nutritional education \\
& Emotive eating education \\
School & Lifestyle education \\
& Provision of healthy foods \\
& Nutritional education \\
& Healthy environment with availability of healthy food and water \\
& Allow physical activity \\
& Physical activity education \\
& Education \\
Community & Taxation for unhealthy foods and beverages \\
& Industries incentives for heathy food and beverages \\
& Control of school meal \\
& Open free space for physical activity in urban areas \\
Incentives for rural areas and low income families
\end{tabular}


Table 2 Preventive intervention according to children age

\begin{tabular}{ll}
\hline Age & Intervention \\
\hline Birth-2 years & Promote exclusive breastfeeding \\
& Controlled protein intake \\
& Avoid sugar sweetened beverages \\
& Promote variety of foods \\
& Avoid restrictive feeding habits \\
& Avoid screen time \\
& Promote education and food knowledge \\
& Avoid sugar sweetened beverages \\
& Five meals a day \\
& 60 min of physical activity daily \\
& Reduce screen time \\
& Five portions of fruit and vegetables daily \\
& Allow child to choose the snack \\
& 60 min of physical activity daily \\
& Teach how to plan and prepare meals \\
\hline $13-18$ years &
\end{tabular}

Family-based intervention programs have been associated with a significant improvement in adiposity measures and cardiometabolic risk profile. Moreover, children in the intervention group displayed a healthier eating pattern compared to control group [58-61].

\section{School-based interventions}

Schools have a pivotal role in children education, therefore they figure among the most relevant settings in childhood obesity prevention. Schools provide education, meals, and can promote healthy lifestyle.

A body of literature reports that students benefit of healthier school environment [62-67]. Intervention programs differ in terms of length, type of intervention (i.e. nutrition and/or physical activity), and target (i.e. students and/or families), however, they have promising results. Among the targets, reduction of sugar sweetened beverages has been evaluated. A cost-effectiveness analysis based on installation of free water dispensers on school lunch lines showed a significant reduction of economic costs through reduction of childhood obesity [64]. Other intervention programs have focused on eating education and knowledge promotion. The intervention group showed BMI reduction and lower consumption of unhealthy food and sugar sweetened beverages $[63,68]$. Similarly, prevention via implementation of physical activity in school settings reported significant improvement in terms of adiposity measures and healthy behavioral changes [69].

In conclusion, current literature suggests that obesity prevalence can be slightly lowered through school interventions with a multicomponent approach (nutrition and physical activity). The wide heterogeneity of the studies may limit the exact identification of a welldefined program. Further research is needed to investigate the efficacy and long-term outcomes of these interventions.

\section{Public policy interventions}

Although family and school play a key role in children education, children are influenced by a broader social environment. Therefore, community prevention programs should be encouraged. Several different target have been addressed, such as sugar sweetened beverages consumption, social inequalities, urbanization, equitable access to services, positive events, and use of social network [70]. In particular, urbanization is one of the causes of childhood obesity as it has been associated with higher consumption of junk food and sedentary behavior [71]. In fact, the most ranked recommendations for urban communities are the implementation of the public open spaces and the reduction of sport facilities costs [72]. Nevertheless, at the same time urban environment enables a more feasible access to community prevention programs $[73,74]$. In fact, children living in rural areas have a higher risk of obesity than urban counterpart [75]. A systematic review including studies on rural communities has reported effectiveness of policy intervention enhancing opportunity of outside physical activity [76].

During the last years, the reduction of sugar intake has been addressed. Several international societies recommend against the assumption of sugary drinks especially during the first years of life [77]. Therefore, a body of intervention against the consumption of sugar sweetened beverages has been promoted. In particular, several national policy have undertaken taxation of sugary drinks [78-83]. A systematic review reported that for each $10 \%$ increase in sugary drinks price with a tax it is estimated a reduced sugary drink consumption by $7 \%$ [84]. Sugary drinks taxation appears as one of the most promising prevention programs according to modeling studies and it can be of more impact if associated with other interventions enabling access to healthy foods [85, 86]. Another approach is the use of low-calorie sweeteners that contain no or few added sugars that have been associated with contrasting results [87].

While there is promising evidence of community based single intervention efficacy, there are limited data and knowledge for the multiple level interventions and how to combine the different interventions for obesity prevention.

\section{Conclusions}

Prevention appears the most promising tool to counteract obesity epidemic. Education toward healthy nutrition and active lifestyle constitutes the basis of every type of intervention program. A multicomponent and multilevel 
approach involving community, school, and family might be more effective than single component programs. However, more research is needed to characterize and standardize the most effective protocol in terms of feasibility, sustainability, cost-effectiveness, and long-term outcomes.

\section{Acknowledgements \\ Not applicable.}

\section{Authors' contributions}

RR and GRU wrote the manuscript, MGC, MDN, and GG performed the literature search, NC and EMDG revised the manuscript. All the authors approved the final version of the manuscript.

\section{Funding}

The authors have received no founding for this work

\section{Availability of data and materials}

Not applicable.

\section{Ethics approval and consent to participate}

Not applicable.

\section{Consent for publication}

Not applicable.

\section{Competing interests}

Nothing to declare.

\section{Author details}

'Clinical Nutrition Unit -Santobono-Pausilipon Children's Hospital, Naples, Italy. ${ }^{2}$ Department of the Woman, of the Child, of General and Specialized Surgery, University of Campania "Luigi Vanvitelli", Via L. de Crecchio, 2, 80138 Naples, Italy

Received: 7 May 2020 Accepted: 14 July 2020

Published online: 24 July 2020

\section{References}

1. WHO. Childhood overweight and obesity. 2019. Available from: https:// www.who.int/dietphysicalactivity/childhood/en/.

2. Obesity and overweight. https://www.who.int/health-topics/obesity\#tab= tab_1. Accessed 17 July 2020

3. Collaboration NCDRF. Worldwide trends in body-mass index, underweight, overweight, and obesity from 1975 to 2016: a pooled analysis of 2416 population-based measurement studies in 128.9 million children, adolescents, and adults. Lancet. 2017;390(10113):2627-42.

4. Epicentro. Okkio alla salute 2016. Available from: https://www.epicentro.iss. it/okkioallasalute/dati2016. Accessed 17 July 2020.

5. Valerio G, Maffeis C, Saggese G, Ambruzzi MA, Balsamo A, Bellone S, et al. Diagnosis, treatment and prevention of pediatric obesity: consensus position statement of the Italian Society for Pediatric Endocrinology and Diabetology and the Italian Society of Pediatrics. Ital J Pediatr. 2018:44(1):88.

6. Di Sessa A, Umano GR, Miraglia Del Giudice E, Santoro N. From the liver to the heart: cardiac dysfunction in obese children with non-alcoholic fatty liver disease. World J Hepatol. 2017;9(2):69-73.

7. Deeb A, Attia S, Mahmoud S, Elhaj G, Elfatih A. Dyslipidemia and fatty liver disease in overweight and obese children. J Obes. 2018;2018:8626818.

8. Freedman DS, Mei Z, Srinivasan SR, Berenson GS, Dietz WH. Cardiovascular risk factors and excess adiposity among overweight children and adolescents: the Bogalusa heart study. J Pediatr. 2007:150(1):12-7 e2.

9 Ward Z, Long MW, Resch SC, Giles CM, Cradock AL, Gortmaker SL. Simulation of growth trajectories of childhood obesity into adulthood. N Engl J Med. 2017:377(22):2145-53.

10. Bjerregaard LG, Baker JL. Change in overweight from childhood to early adulthood and risk of type 2 diabetes. N Engl J Med. 2018:378(26):2537-8.

11. Turer CB, Brady TM, de Ferranti SD. Obesity, hypertension, and dyslipidemia in childhood are key modifiable antecedents of adult cardiovascular disease: a call to action. Circulation. 2018;137(12):1256-9.
12. Charakida M, Deanfield JE. BMI trajectories from childhood: the slippery slope to adult obesity and cardiovascular disease. Eur Heart J. 2018;39(24): 2271-3.

13. Singh AS, Mulder C, Twisk JW, van Mechelen W, Chinapaw MJ. Tracking of childhood overweight into adulthood: a systematic review of the literature. Obes Rev. 2008;9(5):474-88.

14. Reilly JJ, Kelly J. Long-term impact of overweight and obesity in childhood and adolescence on morbidity and premature mortality in adulthood: systematic review. Int J Obes. 2011;35(7):891-8.

15. Grandone A, Di Sessa A, Umano GR, Toraldo R, Miraglia Del Giudice E. New treatment modalities for obesity. Best Pract Res Clin Endocrinol Metab. 2018; 32(4):535-49.

16. Swinburn B, Egger G. Preventive strategies against weight gain and obesity. Obes Rev. 2002;3(4):289-301.

17. Initiatives D. 2018 global nutrition report: shining a light to spur action on nutrition. Bristol: Development Initiatives Poverty Research Ltd; 2018. Available from: https://globalnutritionreport.org/ [cited 2019].

18. Barros FC, Victora CG, Scherpbier R, Gwatkin D. Socioeconomic inequities in the health and nutrition of children in low/middle income countries. Rev Saude Publica. 2010;44(1):1-16.

19. Di Cesare M, Khang YH, Asaria P, Blakely T, Cowan MJ, Farzadfar F, et al. Inequalities in non-communicable diseases and effective responses. Lancet. 2013;381(9866):585-97.

20. Speakman JR, Loos RJF, O'Rahilly S, Hirschhorn JN, Allison DB. GWAS for BMI: a treasure trove of fundamental insights into the genetic basis of obesity. Int J Obes. 2018:42(8):1524-31.

21. Locke AE, Kahali B, Berndt SI, Justice AE, Pers TH, Day FR, et al. Genetic studies of body mass index yield new insights for obesity biology. Nature. 2015;518(7538):197-206

22. Rohde K, Keller M, la Cour PL, Bluher M, Kovacs P, Bottcher Y. Genetics and epigenetics in obesity. Metabolism. 2019;92:37-50

23. Shungin D, Winkler TW, Croteau-Chonka DC, Ferreira T, Locke AE, Magi R, et al. New genetic loci link adipose and insulin biology to body fat distribution. Nature. 2015:518(7538):187-96.

24. Wabitsch M, Funcke JB, von Schnurbein J, Denzer F, Lahr G, Mazen I, et al. Severe early-onset obesity due to bioinactive Leptin caused by a p.N103K mutation in the Leptin gene. J Clin Endocrinol Metab. 2015;100(9):3227-30.

25. Faroogi IS, Wangensteen T, Collins S, Kimber W, Matarese G, Keogh JM, et al. Clinical and molecular genetic spectrum of congenital deficiency of the leptin receptor. N Engl J Med. 2007;356(3):237-47.

26. Yeo GS, Faroogi IS, Aminian S, Halsall DJ, Stanhope RG, O'Rahilly S. A frameshift mutation in MC4R associated with dominantly inherited human obesity. Nat Genet. 1998;20(2):111-2.

27. Montague CT, Faroogi IS, Whitehead JP, Soos MA, Rau H, Wareham NJ, et al. Congenital leptin deficiency is associated with severe early-onset obesity in humans. Nature. 1997;387(6636):903-8.

28. Miraglia del Giudice E, Cirillo G, Santoro N, D'Urso L, Carbone MT, Di Toro R, et al. Molecular screening of the proopiomelanocortin (POMC) gene in Italian obese children: report of three new mutations. Int J Obes Relat Metab Disord. 2001;25(1):61-7.

29. Miraglia Del Giudice E, Cirillo G, Nigro V, Santoro N, D'Urso L, Raimondo P, et al. Low frequency of melanocortin-4 receptor (MC4R) mutations in a Mediterranean population with early-onset obesity. Int J Obes Relat Metab Disord. 2002;26(5):647-51.

30. Herrera BM, Keildson S, Lindgren CM. Genetics and epigenetics of obesity. Maturitas. 2011;69(1):41-9.

31. Fall T, Mendelson M, Speliotes EK. Recent advances in human genetics and epigenetics of adiposity: pathway to precision medicine? Gastroenterology. 2017;152(7):1695-706.

32. van Dijk SJ, Molloy PL, Varinli H, Morrison JL, Muhlhausler BS, Members of Epi S. Epigenetics and human obesity. Int J Obes. 2015;39(1):85-97.

33. Heslehurst N, Vieira R, Akhter Z, Bailey H, Slack E, Ngongalah L, et al. The association between maternal body mass index and child obesity: a systematic review and meta-analysis. PLoS Med. 2019;16(6):e1002817.

34. Roseboom T, de Rooij S, Painter R. The Dutch famine and its long-term consequences for adult health. Early Hum Dev. 2006;82(8):485-91.

35. Godfrey KM, Reynolds RM, Prescott SL, Nyirenda M, Jaddoe WW, Eriksson JG, et al. Influence of maternal obesity on the long-term health of offspring. Lancet Diabetes Endocrinol. 2017;5(1):53-64.

36. Dao MC, Clement K. Gut microbiota and obesity: concepts relevant to clinical care. Eur J Intern Med. 2018;48:18-24. 
37. Azad MB, Konya T, Maughan H, Guttman DS, Field CJ, Chari RS, et al. Gut microbiota of healthy Canadian infants: profiles by mode of delivery and infant diet at 4 months. CMAJ. 2013;185(5):385-94.

38. Backhed F, Ding H, Wang T, Hooper LV, Koh GY, Nagy A, et al. The gut microbiota as an environmental factor that regulates fat storage. Proc Nat Acad Sci U S A. 2004;101(44):15718-23.

39. Suarez-Zamorano N, Fabbiano S, Chevalier C, Stojanovic O, Colin DJ, Stevanovic A, et al. Microbiota depletion promotes browning of white adipose tissue and reduces obesity. Nat Med. 2015;21(12):1497-501.

40. Tremaroli V, Backhed F. Functional interactions between the gut microbiota and host metabolism. Nature. 2012;489(7415):242-9.

41. Larque E, Labayen I, Flodmark CE, Lissau I, Czernin S, Moreno LA, et al. From conception to infancy - early risk factors for childhood obesity. Nat Rev Endocrinol. 2019;15(8):456-78.

42. Victora CG, Bahl R, Barros AJ, Franca GV, Horton S, Krasevec J, et al. Breastfeeding in the 21st century: epidemiology, mechanisms, and lifelong effect. Lancet. 2016:387(10017):475-90.

43. Patro-Golab B, Zalewski BM, Kolodziej M, Kouwenhoven S, Poston L, Godfrey $\mathrm{KM}$, et al. Nutritional interventions or exposures in infants and children aged up to 3 years and their effects on subsequent risk of overweight, obesity and body fat: a systematic review of systematic reviews. Obes Rev. 2016; 17(12):1245-57.

44. Tang M. Protein Intake during the First Two Years of Life and Its Association with Growth and Risk of Overweight. Int J Environ Res Public Health. 2018; 15(8):1742.

45. Weber M, Grote V, Closa-Monasterolo R, Escribano J, Langhendries JP, Dain $\mathrm{E}$, et al. Lower protein content in infant formula reduces BMI and obesity risk at school age: follow-up of a randomized trial. Am J Clin Nutr. 2014; 99(5):1041-51.

46. Lind MV, Larnkjaer A, Molgaard C, Michaelsen KF. Dietary protein intake and quality in early life: impact on growth and obesity. Curr Opin Clin Nutr Metab Care. 2017:20(1):71-6.

47. Campbell KJ, Abbott G, Zheng M, McNaughton SA. Early life protein intake: food sources, correlates, and tracking across the first 5 years of life. J Acad Nutr Diet. 2017;117(8):1188-97 e1

48. Arenz S, Ruckerl R, Koletzko B, von Kries R. Breast-feeding and childhood obesity--a systematic review. Int J Obes Relat Metab Disord. 2004;28(10): 1247-56.

49. Robinson SM, Marriott LD, Crozier SR, Harvey NC, Gale CR, Inskip HM, et al. Variations in infant feeding practice are associated with body composition in childhood: a prospective cohort study. J Clin Endocrinol Metab. 2009; 94(8):2799-805.

50. Blake-Lamb TL, Locks LM, Perkins ME, Woo Baidal JA, Cheng ER, Taveras EM. Interventions for childhood obesity in the first 1,000 days a systematic review. Am J Prev Med. 2016;50(6):780-9.

51. Redsell SA, Edmonds B, Swift JA, Siriwardena AN, Weng S, Nathan D, et al. Systematic review of randomised controlled trials of interventions that aim to reduce the risk, either directly or indirectly, of overweight and obesity in infancy and early childhood. Matern Child Nutr. 2016;12(1):24-38.

52. Hennessy M, Heary C, Laws R, van Rhoon L, Toomey E, Wolstenholme $H_{\text {, }}$ et al. The effectiveness of health professional-delivered interventions during the first 1000 days to prevent overweight/obesity in children: a systematic review. Obes Rev. 2019:20(12):1691-707.

53. Yee $A Z$, Lwin MO, Ho SS. The influence of parental practices on child promotive and preventive food consumption behaviors: a systematic review and meta-analysis. Int J Behav Nutr Phys Act. 2017;14(1):47.

54. Wen LM, Baur LA, Simpson JM, Rissel C, Wardle K, Flood VM. Effectiveness of home based early intervention on children's BMI at age 2: randomised controlled trial. BMJ. 2012;344:e3732.

55. Musher-Eizenman D, Holub S. Comprehensive feeding practices questionnaire: validation of a new measure of parental feeding practices. Pediatr Psychol. 2007;32(8):960-72.

56. van Meer F, van der Laan LN, Charbonnier L, Viergever MA, Adan RA, Smeets PA, et al. Developmental differences in the brain response to unhealthy food cues: an fMRI study of children and adults. Am J Clin Nutr. 2016;104(6):1515-22

57. Dennison BA, Erb TA, Jenkins PL. Television viewing and television in bedroom associated with overweight risk among low-income preschool children. Pediatrics. 2002;109(6):1028-35.

58. Matthan NR, Wylie-Rosett J, Xue X, Gao Q, Groisman-Perelstein AE, Diamantis PM, et al. Effect of a Family-Based Intervention on Nutrient
Biomarkers, Desaturase Enzyme Activities, and Cardiometabolic Risk Factors in Children with Overweight and Obesity. Curr Dev Nutr. 2020;4(1):nzz138.

59. Ho M, Garnett SP, Baur L, Burrows T, Stewart L, Neve M, et al. Effectiveness of lifestyle interventions in child obesity: systematic review with metaanalysis. Pediatrics. 2012;130(6):e1647-71.

60. Brown $\mathrm{CL}$, Perrin EM. Obesity prevention and treatment in primary care Acad Pediatr. 2018;18(7):736-45.

61. Hodgkinson A, Abbott J, Hurley MA, Lowe N, Qualter P. An educational intervention to prevent overweight in pre-school years: a cluster randomised trial with a focus on disadvantaged families. BMC Public Health. 2019:19(1):1430.

62. Verjans-Janssen SRB, van de Kolk I, Van Kann DHH, Kremers SPJ, Gerards S. Effectiveness of school-based physical activity and nutrition interventions with direct parental involvement on children's BMI and energy balancerelated behaviors - a systematic review. PLoS One. 2018;13(9):e0204560.

63. Ickovics JR, Duffany KO, Shebl FM, Peters SM, Read MA, Gilstad-Hayden KR, et al. Implementing school-based policies to prevent obesity: cluster randomized trial. Am J Prev Med. 2019;56(1):e1-e11.

64. Kenney EL, Cradock AL, Long MW, Barrett JL, Giles CM, Ward ZJ, et al. Costeffectiveness of water promotion strategies in schools for preventing childhood obesity and increasing water intake. Obesity (Silver Spring). 2019; 27(12):2037-45.

65. Elinder LS, Patterson E, Nyberg G, Norman A. A healthy school start plus for prevention of childhood overweight and obesity in disadvantaged areas through parental support in the school setting - study protocol for a parallel group cluster randomised trial. BMC Public Health. 2018;18(1):459.

66. Bleich SN, Vercammen KA, Zatz LY, Frelier JM, Ebbeling CB, Peeters A. Interventions to prevent global childhood overweight and obesity: a systematic review. Lancet Diabetes Endocrinol. 2018;6(4):332-46.

67. Luybli M, Schmillen H, Sotos-Prieto M. School-Based Interventions in Low Socioeconomic Settings to Reduce Obesity Outcomes among Preschoolers: A Scoping Review. Nutrients. 2019;11(7):1518.

68. Sanchez-Vaznaugh EV, Sanchez BN, Crawford PB, Egerter S. Association between competitive food and beverage policies in elementary schools and childhood overweight/obesity trends: differences by neighborhood socioeconomic resources. JAMA Pediatr. 2015:169(5):e150781.

69. Yuksel HS, Sahin FN, Maksimovic N, Drid P, Bianco A. School-Based Intervention Programs for Preventing Obesity and Promoting Physical Activity and Fitness: A Systematic Review. Int J Environ Res Public Health. 2020;17(1):347.

70. Brennan LK, Brownson RC, Orleans CT. Childhood obesity policy research and practice: evidence for policy and environmental strategies. Am J Prev Med. 2014;46(1):e1-16

71. Popkin BM, Gordon-Larsen P. The nutrition transition: worldwide obesity dynamics and their determinants. Int J Obes Relat Metab Disord. 2004 28(Suppl 3):S2-9.

72. Diez J, Gullon P, Sandin Vazquez M, Alvarez B, Martin MDP, Urtasun M, et al. A Community-Driven Approach to Generate Urban Policy Recommendations for Obesity Prevention. Int J Environ Res Public Health. 2018;15(4):635.

73. Schultz JA, Collie-Akers VL, Fawcett SB, Strauss WJ, Nagaraja J, Landgraf AJ et al. Association between community characteristics and implementation of community programmes and policies addressing childhood obesity: the healthy communities study. Pediatr Obes. 2018;13(Suppl 1):93-102.

74. Strauss WJ, Nagaraja J, Landgraf AJ, Arteaga SS, Fawcett SB, Ritchie LD, et al. The longitudinal relationship between community programmes and policies to prevent childhood obesity and BMI in children: the healthy communities study. Pediatr Obes. 2018;13(Suppl 1):82-92.

75. Lutfiyya MN, Lipsky MS, Wisdom-Behounek J, Inpanbutr-Martinkus M. Is rural residency a risk factor for overweight and obesity for U.S. children? Obesity (Silver Spring). 2007;15(9):2348-56.

76. Umstattd Meyer MR, Perry CK, Sumrall JC, Patterson MS, Walsh SM, Clendennen SC, et al. Physical activity-related policy and environmental strategies to prevent obesity in rural communities: a systematic review of the literature, 2002-2013. Prev Chronic Dis. 2016;13:E03.

77. Muth ND, Dietz WH, Magge SN, Johnson RK, American Academy Of P, Section On O, et al. Public Policies to Reduce Sugary Drink Consumption in Children and Adolescents. Pediatrics. 2019:143(4):e20190282.

78. Ford CN, Poti JM, Ng SW, Popkin BM. SSB taxes and diet quality in US preschoolers: estimated changes in the 2010 healthy eating index. Pediatr Obes. 2017;12(2):146-54. 
79. Miller CL, Dono J, Wakefield MA, Pettigrew S, Coveney J, Roder D, et al. Are Australians ready for warning labels, marketing bans and sugary drink taxes? Two cross-sectional surveys measuring support for policy responses to sugar-sweetened beverages. BMJ Open. 2019;9(6):e027962.

80. Nakamura R, Mirelman AJ, Cuadrado C, Silva-Illanes N, Dunstan J, Suhrcke M. Evaluating the 2014 sugar-sweetened beverage tax in Chile: an observational study in urban areas. PLoS Med. 2018;15(7):e1002596.

81. Sundborn G, Thornley S, Beaglehole R, Bezzant N. Policy brief: a sugary drink tax for New Zealand and 10,000-strong petition snubbed by minister of health and National Government. N Z Med J. 2017;130(1462):114-6.

82. Scarborough P, Briggs A, Mytton O, Rayner M. The Institute of Fiscal Studies' verdict on a sugary drink tax. Lancet. 2016;387(10024):1162.

83. McCarthy M. Soda tax brings sharp fall in sugary drink consumption in Californian city. BMJ. 2016;355:15940.

84. Afshin A, Penalvo JL, Del Gobbo L, Silva J, Michaelson M, O'Flaherty M, et al. The prospective impact of food pricing on improving dietary consumption: a systematic review and meta-analysis. PLoS One. 2017;12(3)::0172277.

85. Gortmaker SL, Wang YC, Long MW, Giles CM, Ward ZJ, Barrett JL, et al. Three interventions that reduce childhood obesity are projected to save more than they cost to implement. Health Aff (Millwood). 2015;34(11):19329.

86. Fernandez MA, Raine KD. Insights on the influence of sugar taxes on obesity prevention efforts. Curr Nutr Rep. 2019;8(4):333-9.

87. Young J, Conway EM, Rother Kl, Sylvetsky AC. Low-calorie sweetener use, weight, and metabolic health among children: a mini-review. Pediatr Obes. 2019;14(8):e12521

\section{Publisher's Note}

Springer Nature remains neutral with regard to jurisdictional claims in published maps and institutional affiliations.

Ready to submit your research? Choose BMC and benefit from:

- fast, convenient online submission

- thorough peer review by experienced researchers in your field

- rapid publication on acceptance

- support for research data, including large and complex data types

- gold Open Access which fosters wider collaboration and increased citations

- maximum visibility for your research: over $100 \mathrm{M}$ website views per year

At $\mathrm{BMC}$, research is always in progress.

Learn more biomedcentral.com/submissions 